\title{
RESEARCH INTO DYNAMICS OF MOTION PERFORMED by Modular Power Unit as Part of Ploughing TRACTOR-IMPLEMENT UNIT
}

\author{
Volodymyr Bulgakov, Jueri Olt, Semjons Ivanovs, \\ Volodymyr Kuvachov \& Tormi Lillerand
}
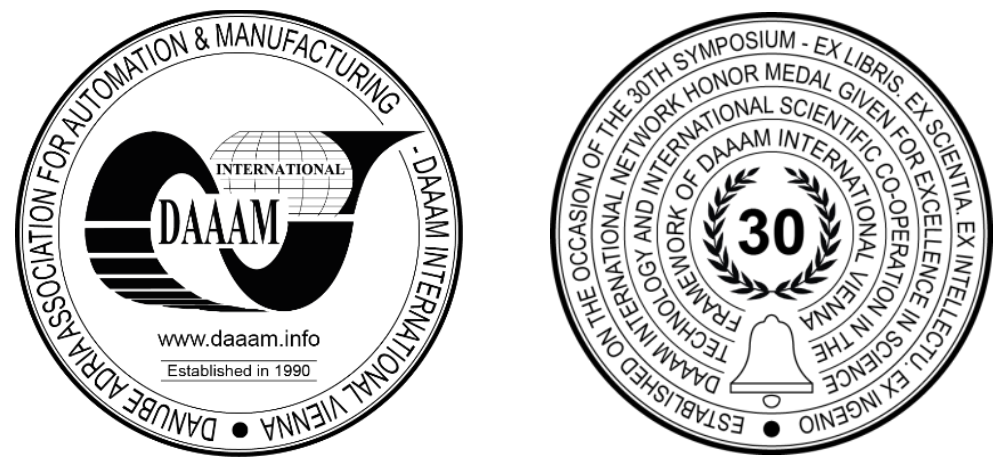

This Publication has to be referred as: Bulgakov, V[olodymyr]; Olt, J[ueri]; Ivanovs, S[emjons]; Kuvachov, V[olodymyr] \& Lillerand, T[ormi] (2021). Research into Dynamics of Motion Performed by Modular Power Unit as Part of Ploughing Tractor-Implement Unit, Proceedings of the 32nd DAAAM International Symposium, pp.0576-0585, B. Katalinic (Ed.), Published by DAAAM International, ISBN 978-3-902734-33-4, ISSN 1726-9679, Vienna, Austria DOI: $10.2507 / 32$ nd.daaam.proceedings.082

\begin{abstract}
The reduction of the power input required for soil ploughing has been and remains one of the most important targets in the agricultural industry. One of the ways of solving this problem is increasing the grip and traction properties of the power unit. This aim can be achieved by introducing an additional process module with drive wheels in the composition of the ploughing tractor-implement unit. As the block-module ploughing unit travels in operation, especially on stubble field, it receives the jolts and impacts caused by the irregularities of the cultivated land, the variation of the plough's tractive resistance and other factors. The generated oscillations of the unit in the vertical plane impair the operator's working conditions, reduce the reliability and decrease the productivity of the unit's operation.
\end{abstract}

Keywords: dynamic system; modelling; modular power unit; smoothness of movement; vertical oscillation.

\section{Introduction}

The reduction of the power consumption in soil ploughing has been and remains one of the most important targets in the agricultural industry [1], [2], [3], [4]. One of the ways to solve this problem is to increase the grip and traction properties of the tractor [5], [6], [7], [8]. As regards the composition of the ploughing tractor-implement unit, this can be implemented by introducing an additional process module with drive wheels, thus forming a modular power unit (Fig. 1) [9], [10], [11]. The main purpose of the process module in the modular power unit is to generate additional tractive effort by using the excess power of the energy intensive tractor's engine [12], [13].

In order to ensure the adequate control and stability of the motion performed by the modular power unit, the process module has to be rigidly connected with the tractor [14], [15]. The immobility of the tractor and the process module relative to each other on the working pass is provided by the automatic locking of the latter's vertical hinge [9]. However, such a design solution provides for the stability and control of the motion performed by the modular power unit under consideration, on the one hand, but impairs the smoothness of its movement, on the other hand. 
That results from the fact that, during the motion in operation of the modular power unit as part of the ploughing unit, it receives the jolts and impacts caused by the irregularities of the cultivated land, the variation of the plough's tractive resistance and other factors. The generated oscillations of the unit in the vertical plane make worse the working conditions for its operator, reduce the reliability and decrease the productivity of its operation.

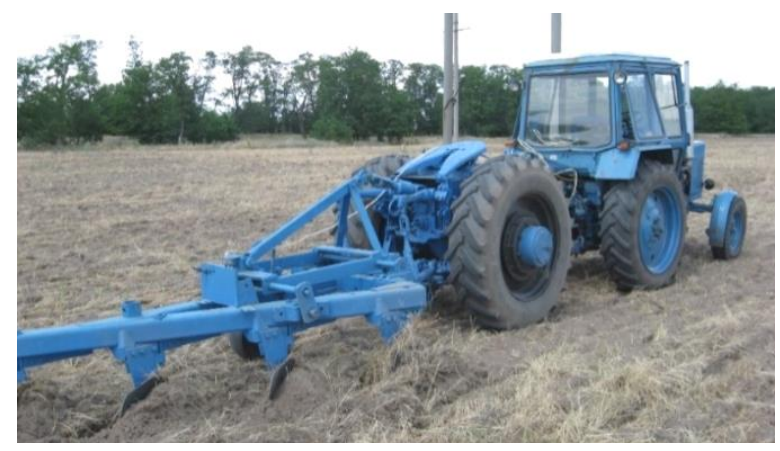

Fig. 1. Modular power unit as part of ploughing unit

In order to eliminate the negative effect of the oscillatory processes in agricultural units, numerous studies have been carried out exploring the effect achieved by introducing various elastic members and damping devices for the purpose of improving the smoothness of motion, [16], [17], [18], [19]. However, the effect that the elastic damping properties of the process module have on the reduction of the vertical oscillations performed by the modular power unit remains unexplored. In view of the above, the problem of designing high-performance and energy-efficient tractor-implement units on the basis of energy intensive tractors, including the approach that suggests improving the grip and traction properties and increasing the tractive effort through the use of a process module with elastic damping properties is a topical one.

The review of the known designs using additional drive axles in tractors [9], [14], [15] has resulted in revealing the general trend in the layout solutions, which suggests making up the traction units on the basis of tractors and process modules. The most effective arrangement of units with tractors and process modules uses the serial connection of the module with the tractor by means of a three-point linkage, which allows one degree of freedom for the motion of the module in the vertical plane. In order to provide for the sufficient manoeuvrability of the tractor with the process module and the agricultural machine, the method of "unit inflection" similar to the hinged frame articulation is employed. The process module is equipped with linkage systems similar to the main linkages of higher draught class tractors for mounting agricultural implements in the field conditions.

Due to its high functional versatility, the modular power unit features a multitude of options for the process part connection arrangement. For example, the employment of the front implement-attaching linkage increases the number of process spaces (Fig. 2) and provides for ganging up wide-span units under several patterns: one implement at the front and two implements behind or two implements at the front and one implement behind with the use of a process container.

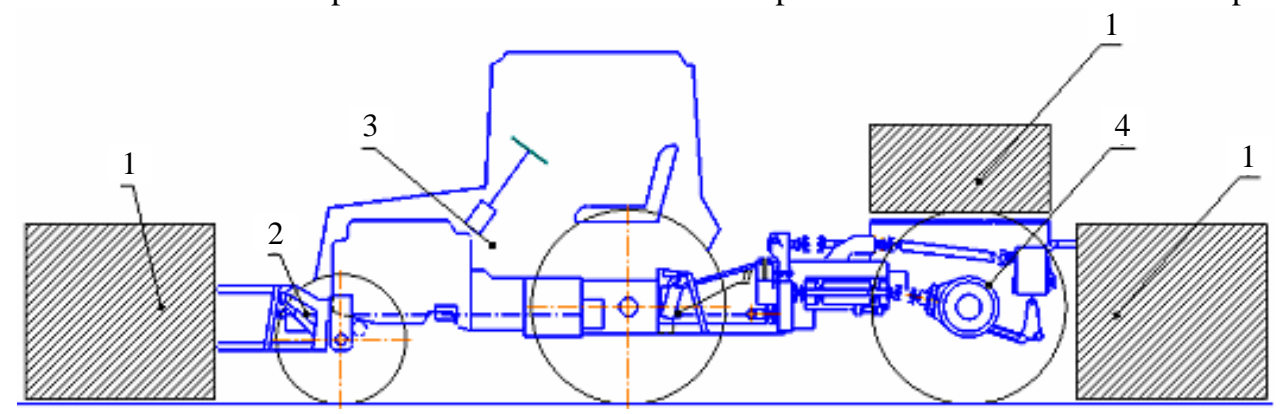

Fig. 2. Process spaces of tractor with process module: 1 - process spaces; 2 - front implement-attaching linkage; 3 tractor; 4 - process module

The completed analysis of the design and operation characteristics of the known modular power and process equipment has proved that, in general, the layout solutions meet the requirements to the configuration of field tractorimplement units and ensure their efficient operation with tractors of draught classes 2 and 3. The review of the known modular power and process equipment has revealed the absence of any practical design solutions and research results regarding the formation of power units with the use of the modular approach. In case of making up modular power units with the use of the modular approach and on the basis of tractors of draught class 1.4 , it is necessary to take into account their intended application as a multi-purpose and ploughing solution for the performance of a certain range of agricultural process operations: first of all, the ploughing ones. Such a layout solution for a multi-purpose and ploughing modular power unit, for example, in ploughing operations will have a negative effect on the smoothness of its movement. 
The performance of the modular power unit as a dynamic system to a considerable extent depends on how individual members of this system are geared up to the operation under the conditions of oscillatory action. In order to eliminate the negative effect of the oscillatory processes, many studies have been carried out with the aim to investigate the effect of installing elastic members and damping devices at different points in the tractor. The modified design facilitates the reduction of the impact that the varying loads have on the tractor as a whole or on its individual assemblies.

Alongside with the positive aspects, it is worthwhile to note that the elastic damping members installed on the wheels transfer significant moments, therefore, such devices are bulky and have insufficient reliability, the drives have low energy capacity. Moreover, they are unable to protect the tractor from the vibration of the uncushioned masses. The linear response of such cushioning systems can bring about resonant modes of operation at some types of work. The pneumohydraulic cushioning systems are of specific interest, because they feature such advantages as a high energy capacity and a possibility to achieve nonlinear response. The use of pneumohydraulic elastic damping cushioning in the drive wheels of the tractor unitised with a five-bottom plough has resulted in the reduction of its vibration by 17-22\%, the slipping of its running gear by 16-20\% and the increase of the productivity by 7-9\% [5], [10], [11], [13].

As has been shown by the studies [18], this approach also produces such a positive by-effect as the damping of the horizontal oscillations generated by the resistance force of the agricultural implement. The oscillation suppression is achieved due to the elasticity of the pneumatic tyres on the wheels and the inertia of the process module's mass. The research into the elastic damping properties of the process module is of special interest, because they can provide for reducing substantially the dynamic load on the tractor as well as improving the vibration protection of the operator.

The aim of the study is to establish the relations representing the impact that the stiffness parameters of the elastic dissipative connection between the tractor and the process module have on the characteristics of the oscillations performed by the ploughing unit in the longitudinal-and-vertical plane, as these relations provide for justifying the rational value of stiffness, i.e. the value, at which the variance of the relative vertical oscillations in the unit reaches the minimum and the amplitude-frequency response comes close to the desirable one.

\section{Materials and Methods}

For the purpose of designing the mathematical model of the motion performed by the modular power unit as part of the ploughing unit in the vertical plane, Lagrange's equations of the second kind have been used [15]:

$\frac{d}{d t}\left(\frac{\partial T_{t}}{\partial \dot{q}_{i}}\right)-\frac{\partial T_{t}}{\partial q_{i}}+\frac{\partial E_{t}}{\partial q_{i}}+\frac{\partial F_{t}}{\partial \dot{q}_{i}}=Q_{i}$,

where $q_{i}, Q_{i}-i$-th generalised coordinate and force, respectively;

$T_{t}, E_{t}$ - kinetic and potential energy of the power unit, respectively;

$F_{t}$ - dissipation function.

In view of the fact that the kinetic energy depends only on the velocity and is independent of the generalised coordinate, the following holds true:

$$
\frac{\partial T_{t}}{\partial q_{i}}=0
$$

Then, with the use of Lagrange's equations of the second kind, the motion of the dynamic system in the vertical plane is described as follows:

$\frac{d}{d t}\left(\frac{\partial T_{t}}{\partial \dot{q}_{i}}\right)+\frac{\partial E_{t}}{\partial q_{i}}+\frac{\partial F_{t}}{\partial \dot{q}_{i}}=Q_{i} \cdot$

The differential equations obtained in this way are solved with the use of the operator calculus methods. In the context of the operator calculus, it is known that, in case of dynamic systems, the main operators are transfer functions and frequency response characteristics. They are just the operators that provide the fullest and physically sound perception of the system's response to various perturbations as well as the transient and constant processes in its operation. Hence, in the process of solving the equations, transfer functions and amplitude-frequency response characteristics of the vertical oscillations have been used as the operators.

In order to calculate the necessary amplitude-frequency characteristics of the vertical oscillations, Lagrange's differential equations of the second kind have to be presented in the operator form. For that purpose, Laplace transformation is applied to the obtained system of differential equations. In accordance with it, the differentiation operator is replaced with the value $i \cdot \omega$ (where $i$-imaginary unit, $i^{2}=1, \omega$-frequency of the perturbing action). After the respective transformations, the transfer functions are obtained, then, finally, the frequency response characteristics of the displacements and accelerations are arrived at: 


$$
\grave{A}_{Z / h}(\omega)=\left[U(\omega)^{2}+V(\omega)^{2}\right]^{\frac{1}{2}}
$$

where $U(\omega), V(\omega)$ - expressions for the real and imaginary components of the frequency response characteristics of the dynamic system under consideration:

$$
\begin{aligned}
& U(\omega)=M \cdot M_{1}+\frac{N \cdot N_{1}}{M_{1}^{2}+N_{1}^{2}}, \\
& V(\omega)=N \cdot M_{1}-\frac{M \cdot N_{1}}{M_{1}^{2}+N_{1}^{2}} .
\end{aligned}
$$

where

$$
\begin{aligned}
& M=b_{0}-b_{2} \cdot \omega^{2}+b_{4} \cdot \omega^{4}, \\
& N=b_{1} \cdot \omega-b_{3} \cdot \omega^{3}+b_{5} \cdot \omega^{5}, \\
& M_{1}=a_{0}-a_{2} \cdot \omega^{2}+a_{4} \cdot \omega^{4}-a_{6} \cdot \omega^{6}, \\
& N_{1}=a_{1} \cdot \omega-a_{3} \cdot \omega^{3}+a_{5} \cdot \omega^{5} .
\end{aligned}
$$

Thus, the obtained amplitude-frequency response characteristics show the amplitude of the vertical accelerations (displacements) produced by the profile of the support surface at the unit amplitude.

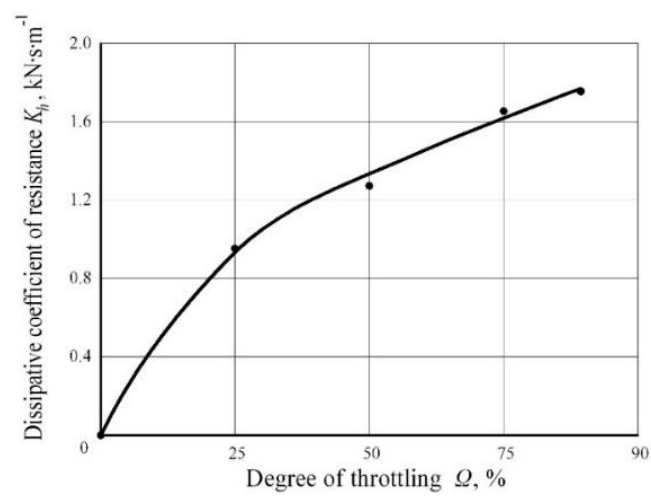

Fig. 3. Nomogram of relation between resistance coefficient $K_{h}$ of elastic dissipative connection between tractor and process module, on one hand, and degree of throttling $\Omega$ in hydraulic system of tractor's rear linkage, on the other hand

In the experiments, the elastic dissipative connection between the tractor and the process module of the modular power unit was established by means of throttling the hydraulic system of the tractor's rear linkage. At the same time, the preliminary laboratory measurements had proved that the degree of throttling $\Omega$ applied to the hydraulic system of the tractor's rear linkage changed the resistance coefficient $K_{h}$ of the elastic dissipative connection between the tractor and the process module in direct proportion (Fig. 2).

\section{Results and Discussion}

The general method of solving the dynamic problems of the interrelated vertical oscillations of the tractor and the process module in the modular power unit as part of the ploughing unit is represented by the system of rather complex differential equations obtained on the basis of Lagrange's equations of the second kind. With the aim of simplifying their generation in the process of mathematical modelling, the following provisions and assumptions have been accepted: for the purpose of generating the equivalent schematic model of the ploughing unit, it is appropriate and sufficient to analyse the oscillations of a plane figure that has the shape of the side projection only in the vertical plane that coincides with the longitudinal symmetry plane of the modular power unit and plough; the motion of the ploughing unit is assumed to be uniform and straight-line and the profile of the supporting surface is assumed to be the same under the wheels of both the right and left sides; during their translation on the field, the wheels of the tractor and the process module remain in constant contact with the surface of the agricultural background, which is represented by a random stationary ergodic function of the travelled distance; the oscillations of the plough's tractive resistance do not have a significant effect on the translational motion velocity of the unit - in view of that, the latter is assumed to be constant; the angular oscillations of the plough can be ignored; at small heading angles $\varphi_{t}$ of the tractor, the following equalities hold true: $\tan \varphi_{t} \approx \varphi_{t}, \cos \varphi_{t}$ $\approx 1$. 
In order to simplify the process of solving the set problem, the equations that describe the vertical oscillations of the modular power unit and the plough are generated separately for each of the components. In accordance with the universally accepted principle of removing the constraints and replacing them by the reaction forces (free-body diagram), the interaction between the tractor and the process module can be expressed in terms of the force $F_{z}$ applied at the instantaneous centre of turn of the tractor's rear linkage (point $O$, Fig. 3). The interaction between the process module and the plough can be represented by the reaction $R_{p}$ applied at the instantaneous centre of turn of the process module's rear linkage (point $C_{p}$, Fig. 4). In accordance with the made assumptions, the real tractor can be represented by the following equivalent dynamic model (Fig. 3).

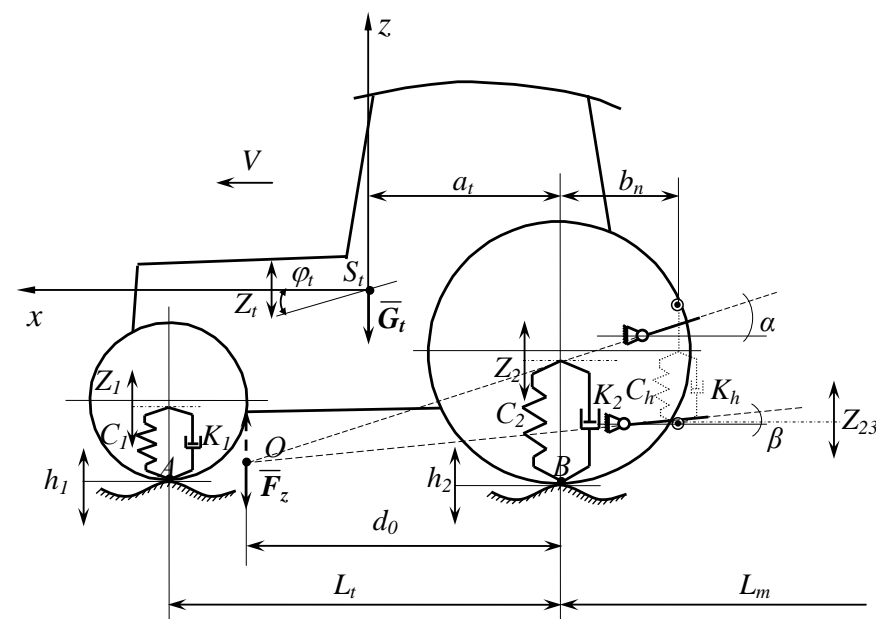

Fig. 4. Analytical model of tractor's oscillations in longitudinal-and-vertical plane

The analytical dynamic model of the two-dimensional motion performed by the tractor in the vertical plane (Fig. 3) has two degrees of freedom: the vertical displacement $\left(Z_{t}\right)$ of its centre of mass (point $S_{t}$ ) and the angular oscillations of its frame $\varphi_{t}$. Similarly, the real process module can be represented by its equivalent dynamic model (Fig. 4).

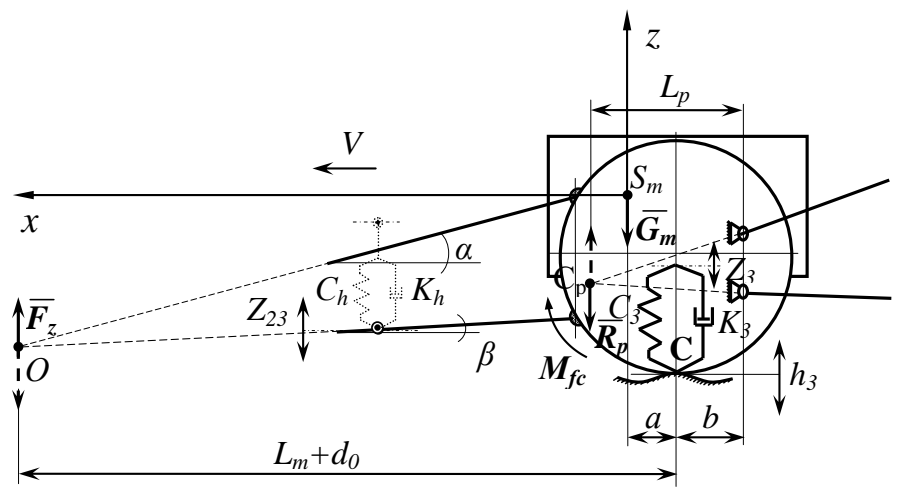

Fig. 5. Analytical model of oscillations performed by process module in longitudinal-and-vertical plane

The analytical dynamic model of the two-dimensional motion performed by the process module in the vertical plane (см. Fig. 4) exhibits only one degree of freedom - the vertical displacement $\left(Z_{3}=Z_{m}\right)$ of its centre of mass (point $\left.S_{m}\right)$. The majority of state-of-the-art ploughs with three to six bodies do not feature elastic members on their carrier wheels. Due to the slipping of the wheels of the tractor and the process module, the longitudinal profile of the track is smoothed out to a certain extent. As a result of that, the variance of the plough's vertical oscillations, when it is unitised with a modular power unit is significantly smaller, than in case of unitising it with a single tractor. Moreover, under the action of the force of gravity $\left(G_{p}\right)$ and the vertical component of the plough's tractive resistance $\left(R_{z}\right)$ (Fig. 5) its carrier wheel deforms the soil even more, which further reduces the heights of the agricultural background profile irregularities. That results in the decreased frequency and energy (variance) of the plough's vertical oscillations, which has a positive effect on the uniformity of cultivation with regard to its depth. Due to the presence of the substantial resultant action of the forces $G_{p}$ and $R_{z}$, the vertical oscillations of the tractor produce little effect on the dynamics of the plough's vertical displacements. Accordingly, it is reasonable to assume that the properties of the plough's vertical oscillations are defined not so much by the dynamics of the ploughing unit motion as by the characteristics of the agricultural background's longitudinal profile. At the same time, the variations of the ploughing depth that exceed the limits set by the agronomical standards $( \pm 2 \mathrm{~cm})$ take place, as is known from the practice, only in case considerable free play is present at the points of connection between the plough and the power unit's linkage. Moreover, such variations are not the same on the whole length of the plough: they are smaller after the passage of the first body, but they are greater after the last body. 


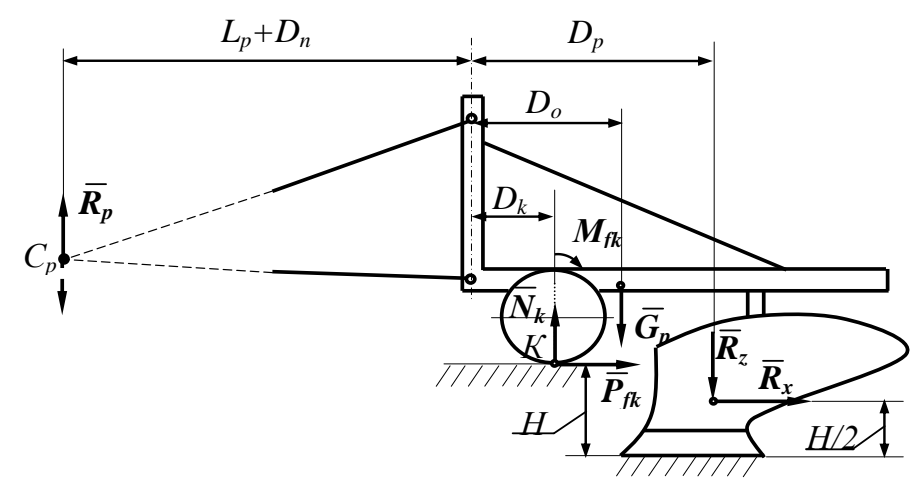

Fig. 6. Schematic model of forces acting on equivalent plough body in longitudinal-and-vertical plane

The following forces act on the equivalent plough body in the longitudinal-and-vertical plane (Fig. 5): $G_{p}-$ force of gravity of the plough; $R_{x}, R_{z}$ - horizontal and vertical components of the forces acting on the plough from the soil; $N_{k}-$ normal reaction on the plough's carrier wheel. Hence, in view of the above-stated, the analytical dynamic model of the ploughing unit based on the modular power unit has three degrees of freedom: the vertical displacement $Z_{t}$ of the tractor's centre of mass, the angular oscillations of its frame $\varphi_{t}$, the vertical displacement $Z_{3}=Z_{m}$ of the centre of mass of the process module. Taking into consideration the following equalities:

$Z_{t}=\frac{Z_{1} a_{t}+Z_{2}\left(L_{t}-a_{t}\right)}{L_{t}}$,

$\varphi_{t}=\frac{Z_{2}-Z_{1}}{L_{t}}$

where $Z_{1}, Z_{2}$ - vertical displacements of the front and rear axles of the power unit, respectively;

$L_{t}, a_{t}$ - base and longitudinal coordinate of the tractor's centre of mass, the vertical displacements $Z_{1}, Z_{2}$ and $Z_{3}$ of the axles in the modular power unit are taken as the generalised coordinates. After finding the kinetic energy $T_{t}$ and the potential energy $E_{t}$ as well as the respective dissipative $F_{t}$ and generalized $Q_{i}$ forces, the mathematical model of the vertical oscillatory motions of the modular power unit as part of a ploughing combined unit is obtained in the form of the following system of differential equations [15]:

$$
\left.\begin{array}{l}
\grave{A}_{11} \cdot \ddot{Z}_{1}+\grave{A}_{12} \cdot \dot{Z}_{1}+\grave{A}_{13} \cdot Z_{1}+\grave{A}_{14} \cdot \ddot{Z}_{2}=f_{11} \cdot \dot{h}_{1}+f_{12} \cdot h_{1}+f_{13} \cdot R_{\tilde{o}}+f_{14}, \\
\grave{A}_{21} \cdot \ddot{Z}_{2}+\grave{A}_{22} \cdot \dot{Z}_{2}+\grave{A}_{23} \cdot Z_{2}+\grave{A}_{24} \cdot \ddot{Z}_{1}=f_{21} \cdot \dot{h}_{2}+f_{22} \cdot h_{2}+f_{23} \cdot R_{\tilde{o}}+f_{24}, \\
\grave{A}_{31} \cdot \ddot{Z}_{3}+\grave{A}_{32} \cdot \dot{Z}_{3}+\grave{A}_{33} \cdot Z_{3}=f_{31} \cdot \grave{h}_{3}+f_{32} \cdot h_{3}+f_{33} \cdot R_{\tilde{o}}+f_{34},
\end{array}\right\}
$$

where $\grave{A}_{11}=\frac{M_{t} \cdot a_{t}^{2}+J_{t}}{L_{t}^{2}}$

$$
\begin{array}{ll}
A_{12}=K_{1} ; A_{13}=C_{1} ; & \grave{A}_{14}=\frac{2\left[M_{t} \cdot a_{t} \cdot\left(L_{t}-a_{t}\right)-J_{t}\right]}{L_{t}^{2}} ; \\
\grave{A}_{21}=\frac{M_{t} \cdot\left(L_{t}-a_{t}\right)^{2}-J_{t} ;}{L_{t}^{2}} ; & \grave{A}_{22}=\hat{E}_{2} ; A_{23}=C_{2} ; \quad \grave{A}_{24}=\frac{2\left[M_{t} \cdot a_{t} \cdot\left(L_{t}-a_{t}\right)-J_{t}\right]}{L_{t}^{2}} ;
\end{array}
$$

$A_{31}=M_{m} ; \grave{A}_{32}=\hat{E}_{3} ; A_{33}=\tilde{N}_{\xi} ;$

$$
f_{11}=K_{1} ; f_{12}=C_{1} ;
$$$$
f_{13}=\frac{d_{0} \cdot\left(L_{p}-b_{m}\right) \cdot\left[0.5 H-0.2\left(D_{p}-D_{k}\right)\right]}{L_{t} \cdot\left(L_{p}+D_{n}+D_{k}\right) \cdot\left(L_{m}+d_{0}\right)} ; f_{14}=\frac{d_{0}}{L_{t} \cdot\left(L_{m}+d_{0}\right)} \cdot\left[G_{m} \cdot\left(a_{m}-f_{m} \cdot r_{k m}\right)-\frac{G_{p} \cdot\left(L_{p}-b_{m}\right) \cdot\left(D_{0}-D_{k}\right)}{\left(L_{p}+D_{n}+D_{k}\right)}\right]
$$$$
f_{21}=K_{2} ; f_{22}=\tilde{N}_{2} ;
$$$$
f_{23}=\frac{\left(1-d_{0} \cdot L_{t}^{-1}\right) \cdot\left(L_{p}-b_{i}\right) \cdot\left[0.5 H-0.2\left(D_{p}-D_{k}\right)\right]}{\left(L_{p}+D_{n}+D_{k}\right) \cdot\left(L_{m}+d_{0}\right)} ; f_{24}=\frac{\left(1-d_{0} \cdot L_{t}^{-1}\right)}{\left(L_{m}+d_{0}\right)}\left[G_{m} \cdot\left(a_{m}-f_{m} \cdot r_{k m}\right)-\frac{G_{p} \cdot\left(L_{p}-b_{m}\right) \cdot\left(D_{0}-D_{k}\right)}{\left(L_{p}+D_{n}+D_{k}\right)}\right]
$$ 


$$
\begin{aligned}
& f_{31}=K_{3} ; f_{32}=\tilde{N}_{3} ; \\
& f_{33}=\frac{\left[0.5 H-0.2\left(D_{p}-D_{k}\right)\right]}{\left(L_{p}+D_{n}+D_{k}\right)} \cdot\left[1-\frac{L_{p}-b_{m}}{L_{m}+d_{0}}\right] ; f_{34}=\frac{G_{p} \cdot\left(D_{0}-D_{k}\right)}{\left(L_{p}+D_{n}+D_{k}\right)} \cdot\left[\frac{L_{p}-b_{m}}{L_{m}+d_{0}}-1\right]-\frac{G_{m} \cdot\left(a_{m}-f_{m} \cdot r_{k m}\right)}{\left(L_{m}+d_{0}\right)} .
\end{aligned}
$$

In the system of equations (9), the following parameters are denoted: $M_{t}, J_{t}$ - mass and moment of inertia in the longitudinal and vertical plane of the power module; $M_{m}, G_{m}$ - mass and gravity force of the process module; $G_{p}$ - gravity force of the plough; $f_{m}, r_{k m}$ - resistance coefficient and rolling radius of the wheels of the process module; $R_{x}$ - horizontal component of the plough tractive resistance; $K_{1}, K_{2}, K_{3}$ and $C_{1}, C_{2}, C_{3}$ - respectively, the reduced resistance coefficients of the dissipative and elastic members in the process of damping the oscillations of the modular power unit, which are described by the following expressions:

$$
\begin{array}{lll}
\hat{E}_{1}=\frac{\hat{E}_{s 1} \cdot \hat{E}_{h} \cdot b_{n}^{2}}{\hat{E}_{h} \cdot b_{n}^{2}+2 \cdot \hat{E}_{s 1} \cdot L_{t}^{2}} ; & \hat{E}_{2}=\frac{\hat{E}_{s 2} \cdot \hat{E}_{h} \cdot\left(L_{t}+b_{n}\right)^{2}}{\hat{E}_{h} \cdot\left(L_{t}+b_{n}\right)^{2}+2 \cdot \hat{E}_{s 2} \cdot L_{t}^{2}} ; & \hat{E}_{3}=\frac{\hat{E}_{s 3} \cdot \hat{E}_{h} \cdot b_{n}^{2}}{\hat{E}_{h} \cdot b_{n}^{2}+2 \cdot \hat{E}_{s 3} \cdot\left(L_{m}-b_{n}\right)^{2}} ; \\
\tilde{N}_{1}=\frac{\tilde{N}_{s 1} \cdot \tilde{N}_{h} \cdot b_{n}^{2}}{\tilde{N}_{h} \cdot b_{n}^{2}+2 \cdot \tilde{N}_{s 1} \cdot L_{t}^{2}} ; & \tilde{N}_{2}=\frac{\tilde{N}_{s 2} \cdot \tilde{N}_{h} \cdot\left(L_{t}+b_{n}\right)^{2}}{\tilde{N}_{h} \cdot\left(L_{t}+b_{n}\right)^{2}+2 \cdot \tilde{N}_{s 2} \cdot L_{t}^{2}} ; & \tilde{N}_{3}=\frac{\tilde{N}_{s 3} \cdot \tilde{N}_{h} \cdot b_{n}^{2}}{\tilde{N}_{h} \cdot b_{n}^{2}+2 \cdot \tilde{N}_{s 3} \cdot\left(L_{m}-b_{n}\right)^{2}}
\end{array}
$$

where $K_{s 1}, K_{s 2}, K_{s 3}$ and $C_{s 1}, C_{s 2}, C_{s 3}$ - respectively, the resistance coefficients of the dissipative and elastic members in the cushioning systems of the axles of the power and process modules.

The nature of other design parameters is made obvious by Fig. 3. If the Laplace transformations are applied to the system of differential equations (9), the following mathematical model in operator notation is obtained for the dynamics of the motion performed in the longitudinal and vertical plane by the modular power unit as part of a ploughing combined unit:

$$
\left.\begin{array}{l}
K_{11} \cdot Z_{1}(s)+K_{12} \cdot Z_{2}(s)+K_{13} \cdot Z_{3}(s)= \\
=F_{11} \cdot h_{1}(s)+F_{12} \cdot h_{2}(s)+F_{13} \cdot h_{3}(s)+F_{14} \cdot R_{x}(s)+F_{15}, \\
K_{21} \cdot Z_{1}(s)+K_{22} \cdot Z_{2}(s)+K_{23} \cdot Z_{3}(s)= \\
=F_{21} \cdot h_{1}(s)+F_{22} \cdot h_{2}(s)+F_{23} \cdot h_{3}(s)+F_{24} \cdot R_{x}(s)+F_{25}, \\
K_{31} \cdot Z_{1}(s)+K_{32} \cdot Z_{2}(s)+K_{33} \cdot Z_{3}(s)= \\
=F_{31} \cdot h_{1}(s)+F_{32} \cdot h_{2}(s)+F_{33} \cdot h_{3}(s)+F_{34} \cdot R_{x}(s)+F_{35},
\end{array}\right\}
$$

where $K_{11}=A_{11} \cdot s^{2}+A_{12} \cdot s+A_{13}$;

$$
\begin{aligned}
& K_{12}=A_{14} \cdot s^{2} ; \quad K_{13}=K_{23}=K_{31}=K_{32}=0 ; \\
& K_{21}=A_{24} \cdot s^{2} ; \quad K_{22}=A_{21} \cdot s^{2}+A_{22} \cdot s+A_{23} ; \\
& K_{33}=A_{31} \cdot s^{2}+A_{32} \cdot s+A_{33} ; \\
& F_{11}=f_{11} \cdot s+f_{12} ; \quad F_{12}=F_{13}=F_{21}=F_{23}=F_{31}=F_{32}=0 ; \quad F_{14}=f_{13} ; F_{15}=f_{14} ; \\
& F_{22}=f_{21} \cdot s+f_{22} ; F_{24}=f_{23} ; \quad F_{25}=f_{24} ; \\
& F_{33}=f_{31} \cdot s+f_{32} ; \quad F_{34}=f_{33} ; \quad F_{35}=f_{44} ; \\
& s=\frac{d}{d t} \text {-operator of differentiation. }
\end{aligned}
$$

In the system of equations (10), the heights of soil surface irregularities under the front $\left(h_{1}\right)$ and rear $\left(h_{2}\right)$ wheels of the power module and the wheels of the process module $\left(h_{3}\right)$ as well as the plough tractive resistance $\left(R_{x}\right)$ act as the input values. The initial parameters comprise the amplitudes of displacements, that is, the oscillations of the front $\left(Z_{1}\right)$ and rear $\left(Z_{2}\right)$ axles of the power module and the oscillations of the process module's frame $\left(Z_{3}\right)$. In case of dynamic systems, the principal operators are transfer functions and frequency-response characteristics. Therefore, the impact that the values of the resistance coefficients of the dissipative and elastic link between the two modules have on the behaviour of the vertical oscillations of the ploughing combined unit has to be estimated with the use of the amplitude-frequency characteristics of the displacements and accelerations observed in the response of the dynamic system to the agronomic background profile irregularities and the variation of the plough tractive resistance. The analysis of the mathematical model (10) has revealed that the main spectrum of the oscillations performed by the modular power unit as part of the ploughing unit is concentrated within the frequency range of $0-16 \mathrm{~s}^{-1}$ (Fig. 6). 
In terms of the dynamic system adequately responding to the impact of the agricultural background profile irregularities, increasing the stiffness of the viscoelastic connection between the tractor and the process module as parts of the unit is an effective measure, because it makes the amplitude-frequency response characteristics closer to the desirable ones. As the degree of throttling in the hydraulic system of the tractor's rear linkage increases to $90 \%$, the amplitudes of the oscillations performed by its rear axle become reduced almost by a factor of 10, while the resonance peaks of the frequency response characteristics shift into the lower frequency range from $16.5 \mathrm{~s}^{-1}$ to $6.0 \mathrm{~s}^{-1}$ and simultaneously their maximum values decrease almost by a factor of 4 (see Fig. 6). That is a positive result in terms of increasing the smoothness of the motion performed by the modular power unit as part of the ploughing unit, because such a follow-up dynamic system tends to copy the agricultural background irregularities without their amplification.

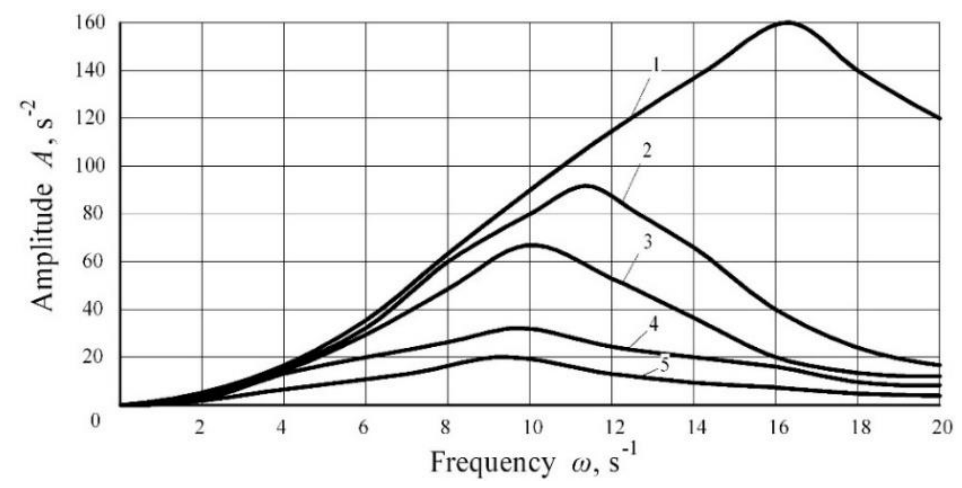

Fig. 7. Amplitude-frequency response characteristics of accelerations during vertical oscillations of tractor's rear axle copying variations in track profile at different degrees of throttling in hydraulic system of tractor's rear linkage

The comparative analysis of the theoretical and experimental amplitude-frequency response characteristics of accelerations during the vertical oscillations of the tractor's rear axle in accordance with the data in Fig. 6 has proved that the discrepancy does not exceed $8-15 \%$, which is acceptable for practical purposes. In accordance with Fisher's ratio test, at a statistical significance level of 0.05 the null hypothesis of the equality of the compared variances is not rejected within the whole variation range of the resistance coefficient of the dissipative connection between the two modules.

According to the results of the analysis carried out with regard to the plotted amplitude-frequency response characteristics of the oscillations performed by the modular power unit as part of the ploughing unit, increasing the stiffness of the connection between the process module and the tractor shifts the frequency response characteristics into the lower frequency range, simultaneously decreasing their maximum values. That makes possible to reduce the variance of the interrelated vertical oscillations in the modular power unit by means of throttling the hydraulic system of the tractor's rear linkage.

The analysis of the plotted amplitude-frequency response characteristics of the vertical oscillations performed by the modular power unit responding to the perturbations caused by the variation of the plough's tractive resistance has proved (Fig. 7) that the oscillations of the tractive resistance offered by the agricultural implements have a significantly smaller effect on the smoothness of its motion, than the oscillations of the longitudinal profile of the track. The maximum value of the oscillation amplitude decreases with the increase of the throttling degree $\Omega$ in the hydraulic system of the tractor's rear linkage. When $\Omega=0 \%$, it is observed at a resonant frequency of $\omega=13.0 \mathrm{~s}^{-1}$ and is equal to just $1.2 \mathrm{~mm} \cdot \mathrm{kN}^{-1}$, while at $\Omega=$ $90 \%$ - it corresponds to a resonant frequency of $\omega=10.0 \mathrm{~s}^{-1}$ and is equal to $0.4 \mathrm{~mm} \cdot \mathrm{kN}^{-1}$. As the value of $\Omega$ rises, the frequency response characteristics subside, their maximums simultaneously shifting into the lower frequency range, which is greatly desired.

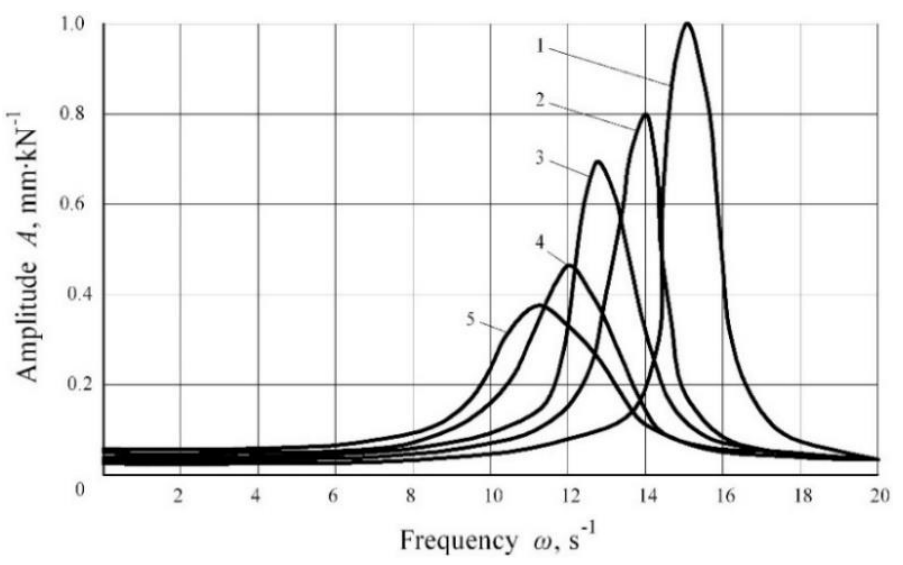

Fig. 8. Amplitude-frequency response characteristics of vertical oscillations performed by tractor's rear axle responding to variations of plough's tractive resistance at different degrees of throttling in hydraulic system of tractor's rear linkage 
It has been established by means of experiments that the range of the root-mean-square deviation of the tractive resistance offered by the plough under the conditions of laboratory-and-field research is $\pm 2.2-3.9 \mathrm{kN}$. Therefore, even at the above-mentioned resonant frequency of $13.0 \mathrm{~s}^{-1}$ (Fig. 7) the mean deviation of the vertical oscillations performed by the modular power unit is expected to be at a level of just $\pm 3-5 \mathrm{~mm}$.

The relation between the amplitude values of the characteristics of the vertical oscillations performed by the modular power unit and the degree of throttling in the hydraulic system of the tractor's rear linkage, when the ploughing unit responds to external perturbations, is not uniform. The intensive decrease in the amplitude values of the accelerations in the vertical oscillations performed by the tractor's rear axle copying variations in the track profile (Fig. 8) takes place, when the degree of throttling in the hydraulic system of the tractor's rear linkage rises up to 60-75\%. The further rise in the throttling applied to the tractor's hydraulic system results in the less significant decrease in the vertical oscillation acceleration amplitudes.

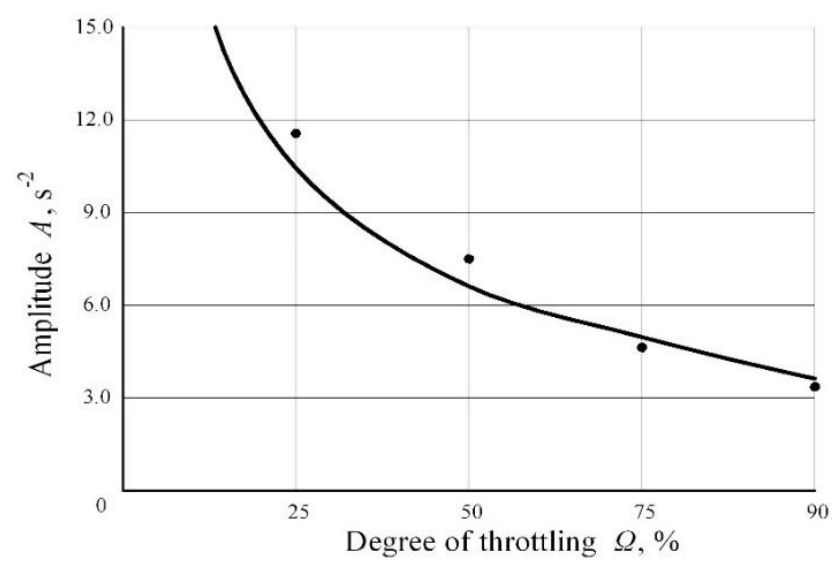

Fig. 9. Relation between amplitude $A$ of tractor's vertical oscillations, when it copies variations in track profile, and degree of throttling $\Omega$ in hydraulic system of its rear linkage

The analysis of the amplitude-frequency response characteristics of the vertical oscillations performed by the tractor's rear axle responding to the variations in the plough's tractive resistance has produced a similar picture (Fig. 9). In the two cases (Fig. 8 and Fig. 9), the critical point is found at a throttling degree of $69.8 \%$. The obtained value is exactly the required rational level of throttling for the hydraulic system of the tractor's rear linkage.

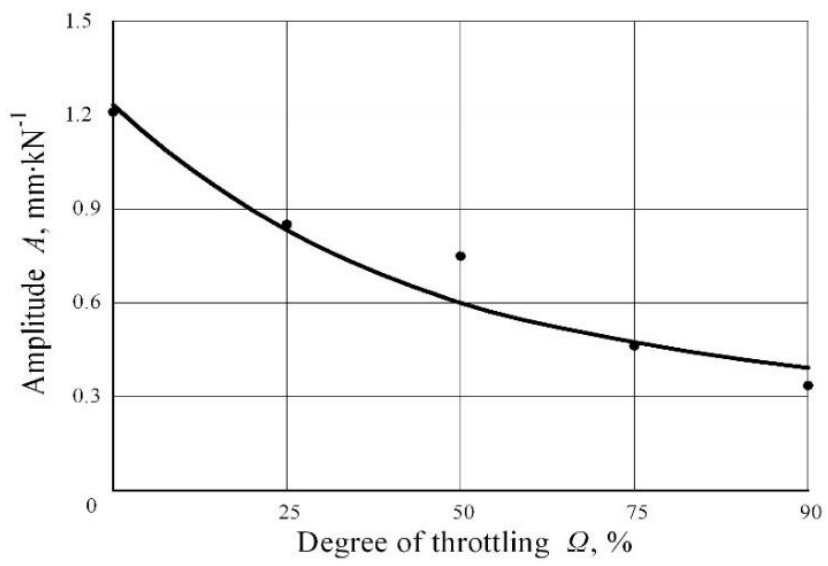

Fig. 10. Relation between amplitude $A$ of tractor's vertical oscillations, when it responds to variations in plough's tractive resistance, and degree of throttling $\Omega$ in hydraulic system of its rear linkage

The analysis of the calculated amplitude-frequency response characteristics of the oscillations performed by the modular power unit as part of the ploughing unit has proved that increasing the stiffness of the connection between the process module and the tractor shifts the frequency response characteristics into the lower frequency range and simultaneously decreases their maximum values. That provides for reducing the variance of the interrelated vertical oscillations in the modular power unit by means of rationally throttling the hydraulic system of the tractor's rear linkage.

\section{Conclusion}

An appropriate mathematical model has been generated for the integrated dynamic system "tractor + process module + plough" enabling the research into the motion of the block-module ploughing unit in the longitudinal-and-vertical plane. 
The analysis of the model has proved that setting the stiffness of the elastic dissipative connection between the tractor and the process module at the rational level allows to reduce the tractor oscillation amplitudes by a factor of 4 to 10 , simultaneously shifting the resonance peaks of the frequency response characteristics into the lower frequency range, that is, from $16.5 \mathrm{~s}^{-1}$ to $6.0 \mathrm{~s}^{-1}$. At the same time, the peaks of the amplitude-frequency response characteristics for the modular power unit responding to the variations in the plough's tractive resistance shift from $13.0 \mathrm{~s}^{-1}$ to $10.0 \mathrm{~s}^{-1}$, while their maximum values become 3 times lower. The overall result is the significantly improved smoothness of the motion performed by the block-module ploughing unit. According to the results of the mathematical modelling, the variation of the tractive resistance offered by the agricultural implements has a 10 times smaller effect on the smoothness of the motion performed by the modular power unit, than the oscillations of the longitudinal profile of the track.

\section{References}

[1] Andreev, A.F.; Kabanau, V.I.; Vantsevich, V.V. (2010). Driveline Systems of Ground Vehicles. Theory and Design. CRC Press, Taylor \& Francis Group, ISBN 978-1-4398-1728-5, 758 p.

[2] Kutzbach H.D. (2000). Trends in Power and Machinery. Journal of Agricultural Engineering Research, Vol. 76, No. 3, pp. 237-247, ISSN 0021-8634. DOI: 10.1006/jaer.2000.0574, available online at http://www.idealibrary.com

[3] Simikič, M.; Dedovič, N.; Savin, L.; Tomič, M.; Ponjičan, O. (2014). Power delivery efficiency of a wheeled traktor at oblique drawbar force. Soil and Tillage Research, Vol. 141, pp. 32-43.

[4] Steindorff, K.; Flecczoreck, T.; Kattenstroth, R.; Schattenberg, J.; Jünemann, D.; Robert, M.; Wulfmeier, K. (2010). Trends in agricultural machines and tractors: Observations on the occasion of the Agritechnica in Hannover. Olhydraulik und Pneumatik, Vol. 54, pp. 57-63.

[5] Bulgakov, V., Adamchuk, V., Kuvachov, V., Arak, M. \& Olt, J. (2017). Study into movement of wide span tractors (vehicles) used in controlled traffic farming. - In: Proceedings of the 28th DAAAM International Symposium: 28th DAAAM International Symposium "Intelligent Manufacturing and Automation" (Ed. B. Katalinic). 2017 November 08-11, Zadar, Croatia, Vienna, Austria: DAAAM International Vienna, 0199-0208.10. 2507/28th.daaam.proceedings.027.

[6] Hac, A., Fulk, D. \& Chen, H., 2008. Stability and Control Considerations of Vehicle-Trailer Combination. SAE Int. J. Passeng. Cars - Mech. Syst. Vol. 1, pp. 925-937. https://doi.org/10.4271/2008-01-1228.

[7] Song, P., Zong, C. \& Tomizuka, M. (2014). A terminal sliding mode based torque distribution control for an individual-wheel-drive vehicle. J. Zhejiang Univ. Sci. A, Vol. 15, 681-693. https://doi.org/10.1631/jzus.A1400101

[8] Szakács, T. (2010). Developing stability control theories for agricultural transport systems. Acta Polytechnica Hungarica, Vol. 7, No 2, pp. 25-37.

[9] Bulgakov, V., Holovach, I., Nadykto, V., Parakhin, O., Kaletnik, N., Shymko, L., Olt, J. (2020a). Motion stability estimation for modular traction vehicle-based combined unit. Agronomy Research. Vol. 18, No. 4, pp. $2340-2352$. doi: 10.15159/AR.20.183.

[10] Nadykto V. (2010). Modular energy units. The Ukrainian Farmer. Vol. 7, pp. 70-71. (In Ukrainian).

[11] Nadykto, V. (2010). The role of modular power units in the formation of the type of tractors in Ukraine. Tractors and agricultural machinery. Vol. 6, pp. 22-25. (In Russian).

[12] Bulgakov, V., Nadykto, V., Kyurchev, S., Nesvidomin, V., Ivanovs, S., Olt, J. (2019). Theoretical background for increasing grip properties of wheeled tractors based on their rational ballasting. Agraarteadus/Journal of Agricultural Science XXX, p-ISSN 1024-0845, e-ISSN 2228-1893, Vol. 30, No. 2, pp. 78-84. DOI: 10.15159/jas.19.07.

[13] Nadykto, V. (2012). Role of tractors' energy saturation rate in making of their range. Tractors and agricultural machinery 3, 16-21.

[14] Bulgakov, V., Kyurchev, V., Nadykto, V., Olt, J. (2015). Structure development and results of testing a novel modular power unit. Agriculture and Agricultural Science Procedia, ISSN 2210-7843, Vol. 7, pp. 40-44, DOI: 10.1016/j.aaspro.2015.12.028.

[15] Bulgakov, V., Kuvachov, V., Olt, J. (2020b). Theory of smoothness of movement of multiple-axle agricultural combined tractor-implement units, Proceedings of the 31st DAAAM International Symposium, pp.0056-0065, B. Katalinic (Ed.), Published by DAAAM International, ISBN 978-3-902734-29-7, ISSN 1726-9679, Vienna, Austria. DOI: $10.2507 / 31$ st.daaam.proceedings.008.

[16] Bulgakov, V., Kuvachov, V. \& Olt, J. (2019a). Theoretical Study on Power Performance of Agricultural Gantry Systems. - In: 30th International DAAAM Symposium "Intelligent Manufacturing \& Automation" (Ed. B. Katalinic). Zadar, 2019 October 23.-26, Vienna, Austria: DAAAM International: 0167-0175. 10.2507/30th.daaam.proceedings.022.

[17] Sidorov, M.V. (2014). Elastic-damping properties of the transport and technological module as part of an agricultural machine-tractor unit. International Research Journal. Vol. 41, No. 10-2, pp. 119-121. (In Russian).

[18] Sidorov M.V. (2016) Increasing efficiency of use machine-tractor unit due to the application of the technological module with leading engines for tractor class 1.4. Ph.D. Dissertation, Institute of Mechanical and Power Engineering, Russian State Agrarian University, Kaluga, 153 p. (In Russian).

[19] Sudin J.; Gritsik B. (1989). Self-propelled machines for chemicalization. Tractors and agricultural machinery. Vol. 7 pp. 40-42. (In Russian). 